\title{
Observing the Peripheral Burning of Cigarettes by an Infrared Technique*
}

\author{
by \\ C. Liu and D. Woodcock
}

British American Tobacco, R\&D Centre, Regents Park Road, Millbrook, Southampton SO15 8TL, United Kingdom

\section{SUMMARY}

A modern infrared camera was used to observe the peripheral burning of cigarettes during puffing and smouldering. The computer-controlled infrared system captured thermal images with recording rates up to $50 \mathrm{~Hz}$ at 8-bit (256-colour) resolution. The response time was less than $0.04 \mathrm{~s}$ at ca. $780{ }^{\circ} \mathrm{C}$. The overall performance of the system was superior to most infrared systems used in previously reported investigations. The combined capacity allowed us to capture some faster, smaller high-temperature burning events on the periphery of a cigarette during puffing, which was first described by EGERTION et al. in 1963 using an Xray method. These transient burning events were caused by tobacco shreds near the coal surface experiencing the maximum air influx. The temperature of these transient burning events could be ca. 200 to $250{ }^{\circ} \mathrm{C}$ higher than the average peripheral temperature of the cigarette. The likelihood of these high-temperature burning events occurring during smouldering was significantly less. Some other details of the cigarette's combustion were also observed with improved simplicity and clarity. [Beitr. Tabakforsch. Int. 20 (2002) 257-264]

\section{ZUSAMMENFASSUNG}

Mithilfe einer Infrarotkamera wurde das periphere Abbrennen von Cigaretten während eines Zuges und während der Glimmphase untersucht. Das computergestützte Infrarotsystem machte thermische Bilder mit einer Aufnahmegeschwindigkeit von bis zu $50 \mathrm{~Hz}$ und einer Auflösung von 8 Bit (256 Farben). Die Ansprechzeit betrug weniger als 0.04 Sekunden bei einer Temperatur von $780{ }^{\circ} \mathrm{C}$. Das System war leistungsfähiger als die meisten Infrarotsysteme, die bei früheren Untersuchungen eingesetzt wurden. Das kombinierte Leistungsvermögen ermöglichte es uns, einige schnellere und kleinere Ereignisse aufzunehmen, die bei hohen Temperaturen an der Peripherie einer Cigarette während des Zuges stattfinden, was von EGERTION et al. mit Hilfe einer Röntgenstrahlenmethode im Jahre 1963 zum ersten Mal beschrieben wurde. Diese vorübergehenden Verbrennungsspitzen wurden von Tabakfasern nahe der Oberfläche der Cigarette verursacht, wo ein maximaler Luftstrom zu verzeichnen ist. Die Temperatur dieser Verbrennungsspitzen könnte ungefähr 200 bis $250{ }^{\circ} \mathrm{C}$ höher sein als die durchschnittlich gemessene periphere Temperatur einer Cigarette. Die Wahrscheinlichkeit dieser Verbrennungsspitzen während der Glimmphase war signifikant niedriger. Einige weitere Besonderheiten beim Abbrennen einer Cigarette wurden ebenfalls auf einfachere Weise und mit verbesserter Auflösung beobachtet. [Beitr. Tabakforsch. Int. 20 (2002) 257-264]

\section{RESUME}

À l'aide d'une caméra infra-rouge la combustion à la périphérie d'une cigarette au cours de combustion ou en combustion libre a été observée. Le système infra-rouge assisté par ordinateur a capturé des images thermiques à un taux d'enregistrement allant jusqu'à $50 \mathrm{~Hz}$ avec une résolution de 8 bit ( 256 couleurs). Le temps de réponse était inférieur à 0.04 secondes à une température d'environ $780^{\circ} \mathrm{C}$. La performance globale du système était supérieure à la plupart des autres méthodes infra-rouges utilisées dans des investigations antérieures. La capacité combinée a permis de capturer des événements plus rapides et plus petits ayant lieu pendant les bouffées à une température élevée à la périphérie d'une cigarette. Ceci a été rapporté pour la première fois en 1963 par EGERTION et al., à l'aide d'une analyse par rayons X. Ces événements de combustion transitoire ont été causés par des brins de tabac à proximité de la surface de la cigarette ou on observe un flux d'air maximal. La température de ces événements de combustion transitoire peut être supérieure d'environ 200 à $250^{\circ} \mathrm{C}$ à la 


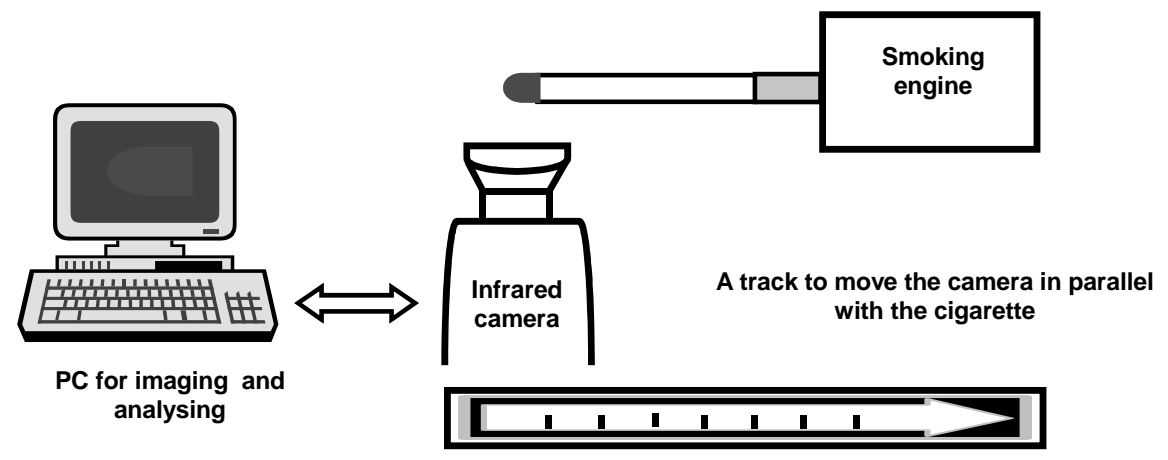

Figure 1. A schematic diagram of the experimental set-up for measuring cigarette peripheral temperature

température moyenne dans les zones périphériques de la cigarette. Au cours de la combustion libre la probabilité de ces événements de combustions à température élevée a été significativement plus réduite. En plus, d'autres détails de la combustion de cigarettes ont également été observés d'une façon plus simple et plus claire. [Beitr. Tabakforsch. Int. 20 (2002) 255-264]

\section{INTRODUCTION}

Extensive work has been carried out to measure the burning temperature of a cigarette since the 1960s (1-7). Particularly those by BAKER $(1,3,4,6)$ have provided fundamental knowledge about the combustion/pyrolysis processes during smouldering and puffing of a cigarette. From the 1980s experimental studies on the burning temperatures of cigarettes became less reported and computer modelling was adopted as a tool for combustion research on cigarettes (7). This, however, does not mean the need for experimental research in this area no longer exists, as pointed out by BAKER and ROBINSON (7) in their review on cigarette combustion: "cigarette design remains semi-empirical in form and continues to draw on experimental measurements as a means of refinement".

Before starting to describe the current work, it may be useful to review the concept of three different temperatures first described by BAKER $(3,4)$. Each of the three types of temperature has its unique physical meaning depending on the nature of the process and the measuring techniques:

- Solid-phase temperature: The temperature of the combusting solids (usually blended tobacco shreds) inside the cigarette coal. It was measured by a fibre-optic infrared probe inside the coal (3). The temperature was position-dependent, and has been used for heat/mass transfer calculations. Solid-phase temperatures normally range from $790{ }^{\circ} \mathrm{C}$ for smouldering to $900{ }^{\circ} \mathrm{C}$ during puffing.

- Gas-phase temperature: The temperature incurred by gas convection inside and around the coal, often measured with a thermocouple and referred to as "the combustion temperature of the cigarette" without clarification in earlier papers (e.g., 8). The temperature is position and gas convection dependent, normally ranging from $790{ }^{\circ} \mathrm{C}$ at smouldering to $860{ }^{\circ} \mathrm{C}$ during puffing. The thermocouple technique used to measure it is intrusive and can cause heat losses.
- Surface temperature: The temperature of the solidphase at the periphery of a burning cigarette, measured by an infrared technique. Easy to measure and the least intrusive. Since the temperature at the coal centre does not change significantly from smouldering to puffing, monitoring the peripheral temperature variations was often sufficient for most purposes. Normally ranging from $675{ }^{\circ} \mathrm{C}$ during smouldering to $930{ }^{\circ} \mathrm{C}$ during puffing.

BAKER and others also pointed out that (1-7): solid- and gas-phase temperatures were different during puffing and became closer (equilibrium) towards the end of the puff and during smouldering. The maximum gas-phase temperature existed in the coal centre whereas the maximum solidphase temperature occurred on the coal surface (ca. $1 \mathrm{~mm}$ ahead of the burn line). Generally, the three temperatures measured by various techniques rarely exceeded about $1000{ }^{\circ} \mathrm{C}$. However, EGERTON et al. discovered some shortlived, "hot spots" on the coal's surface with temperatures close to $1200{ }^{\circ} \mathrm{C}$ by observing the melting of metal particle inclusions in a cigarette using X-ray (5). No confirmation about these fast, high-temperature burning events was reported since then by other techniques.

\section{EXPERIMENTAL}

The infrared system used in this work consisted of a digital infrared camera (an AGEMA THV570 from AGEMA Infrared Systems, Sweden), a personal computer (Windows NT 4.0) for camera control and image analysis, and a dedicated hard-disk for image recording and storage. The combined system had a maximum image recording rate of ca. $50 \mathrm{~Hz}$ ( 1 frame per $0.02 \mathrm{~s}$ ) and an image resolution of 8-bit (256 colour) fixed at all recording rates. This image resolution was sufficient to observe the behaviour of individual tobacco shreds with up to 150 cuts per inch (c.p.i.) (ca. $0.20 \mathrm{~mm}$ ). The basic experimental set-up involved a single-port Borgwaldt smoking engine, with the infrared camera fastened to a fixed track running parallel to a cigarette (Figure 1).

The infrared system was supplied with factory calibration. However, its response time and focal depth to a small, shred-shaped high-temperature object were important in this work and were therefore further tested. This was carried out by using a mains-powered cigarette lighter heating a $0.8 \mathrm{~mm}$ diameter nickel-chromium alloy wire. To 


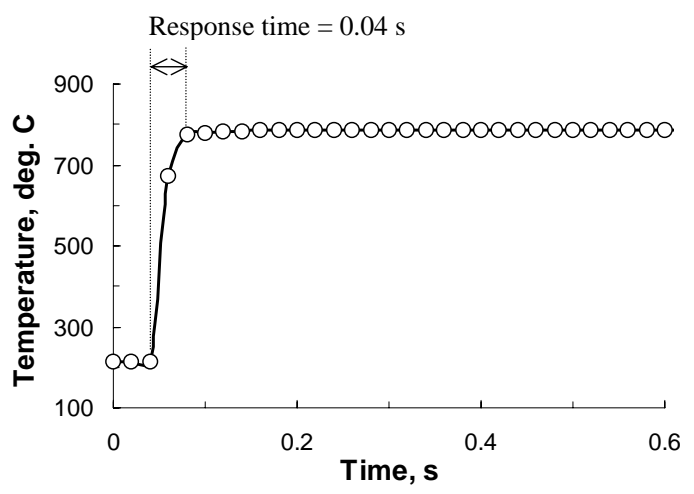

Figure 2. The response time of the AGEMA THV570 system measured by using a pre-heated alloy wire at $780^{\circ} \mathrm{C}$. The low temperature plateau (ca. $220^{\circ} \mathrm{C}$ ) was the detection limit and the high temperature plateau was the stable temperature of the wire.

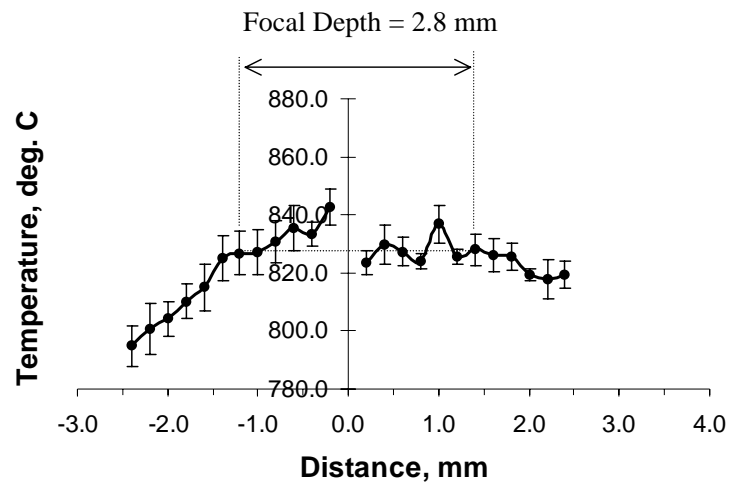

Figure 3. A temperature vs. distance profile was used to determine the focal depth of the infrared camera (determined to be $2.8 \mathrm{~mm}$ from the graph). The error bars represent the standard deviation from 10 repeating measurements

measure the response time, the wire was heated to its stable temperature (ca. $780{ }^{\circ} \mathrm{C}$ ) and a section of the wire was focused and then blocked from the camera's view. The block was then quickly removed and the time to restoration of the original temperature recorded. This is shown in Figure 2. The camera's response took less than $0.04 \mathrm{~s}$ to reach the stable temperature.

The focal depth of an infrared camera is another important parameter, as it determines the distance below or above the optical focus plane from which heat emission (hence temperature) is detected. This capacity is especially useful when dynamic heat exchange takes place, as, for example, during puffing of a cigarette. To determine this parameter a section of mains-powered alloy wire was fastened onto a digital vernier height gauge (with an accuracy of $0.001 \mathrm{~mm}$, manufactured by MITUTOYO [Andover, Hampshire, UK]) and was moved in or out of the camera's focus at increments of $0.2 \mathrm{~mm}$. The temperature profile (averaged for a $60 \mathrm{~s}$ period after stabilisation) against the focus distance was measured and plotted in Figure 3. The plateau at ca. $830{ }^{\circ} \mathrm{C}$ was the wire's stable temperature. The camera's focal depth was experimentally determined to be the horizontal distance in Figure 3 that maintained a near constant temperature while the wire was moved. As Figure 3 shows that the focal depth was ca. $2.8 \mathrm{~mm}$. In other
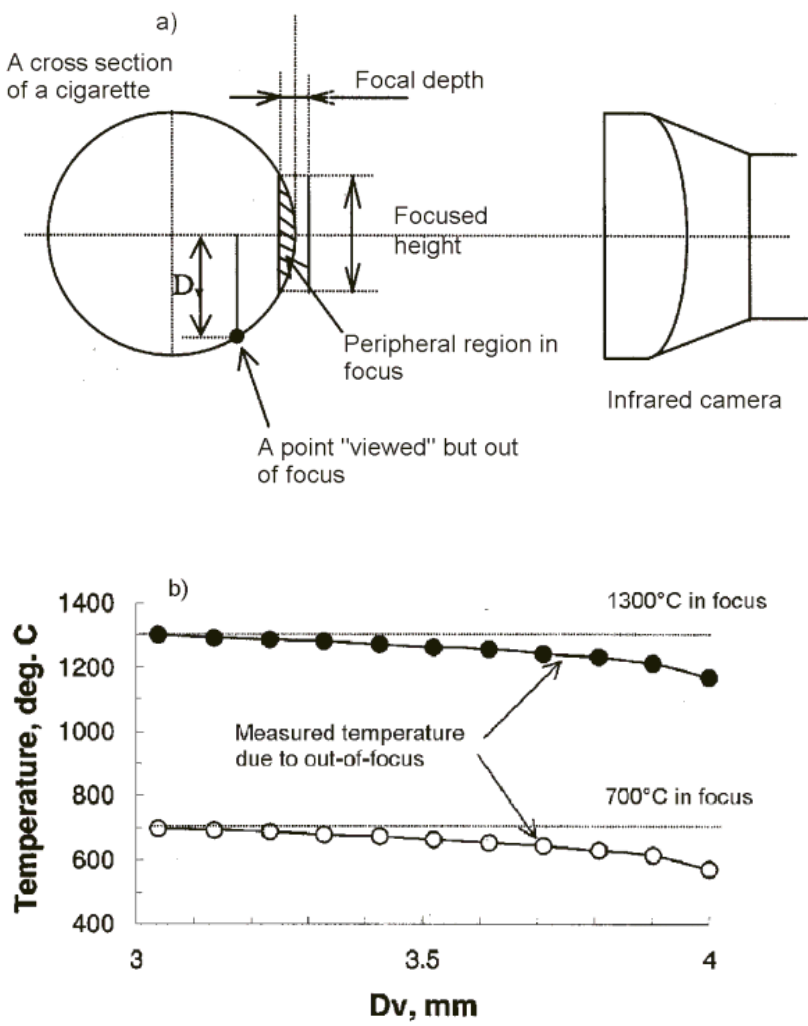

Figure 4. A schematic drawing to illustrate the effect of the infrared camera's focal depth on the accuracy of temperature measurement (a); a plot of the measured temperature against the vertical out-of-the-focus distance (Dv) at two assumed temperature values $(b)$

words, the maximum depth from which accurate tempera ture was measured by the infrared camera was no deeper than $2.8 \mathrm{~mm}$. The temperature at the plateau showed some fluctuation at ca. $10{ }^{\circ} \mathrm{C}$, which was caused by the ambient air movement affecting the heat emission from the wire. Assuming half of the focal depth (i.e., $1.4 \mathrm{~mm}$ ) fell at the nearest surface point on a cigarette towards the camera (Figure 4a), which was easily achievable by fixing the camera to a track, the maximum temperature error towards the top or the bottom edges of a horizontally placed cigarette (the furthest away from the focus) was estimated to be ca. $130{ }^{\circ} \mathrm{C}$ (Figure $4 \mathrm{~b}$ ), assuming equal temperature on the entire periphery for a $8 \mathrm{~mm}$ diameter cigarette.

Finally, all data from this work were measured using fluecured blend, filter tipped cigarettes with no ventilation. All cigarettes were conditioned for at least $48 \mathrm{~h}$ at $22{ }^{\circ} \mathrm{C} / 60 \%$ R.H. before testing. The cigarettes were smoked under International Organisation for Standardisation (ISO) standard machine-smoking conditions (i.e., $35 \mathrm{~cm}^{3}$ puff, 2-s duration every $60 \mathrm{~s}$ ).

\section{RESULTS AND DISCUSSION}

\section{Observation of a puff}

The peripheral temperature of a burning cigarette changes dynamically during puffing $(3,4)$. To demonstrate this point, Figure 5a shows the variation of the maximum 

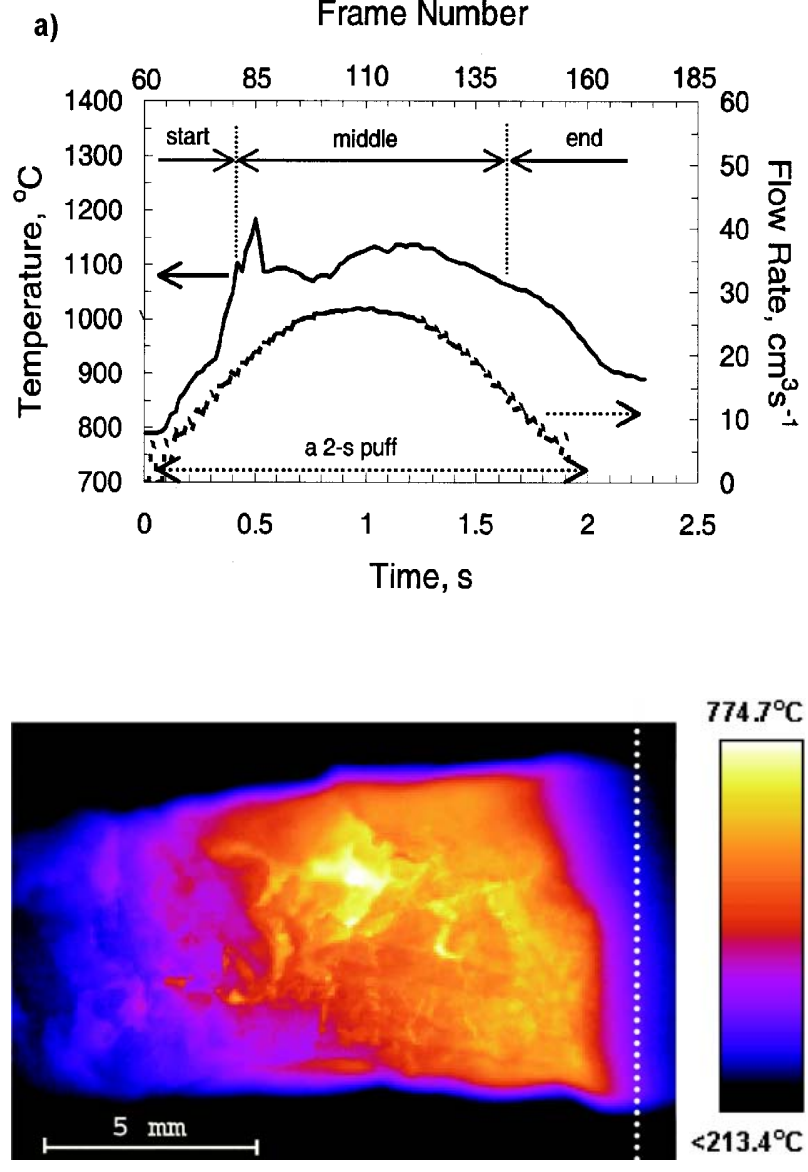

Figure 5. A maximum temperature vs. time (frame number) plot illustrating a $2 \mathrm{~s}$ puff (a) together with the flow rate profile; (b) a thermal image at the starting frame (frame 60, time $=0 \mathrm{~s}$ ) showing the initial state of the cigarette and the position of the paper burn line (the white dashed line). The cigarette was placed horizontally with its unburned rod on the right-hand side (this is true for all thermal images shown in this work).

temperature with the recording time (or frame number) for a 3rd puff smoked under the ISO conditions (35 $\mathrm{cm}^{3} / 2 \mathrm{~s} / 60 \mathrm{~s}$ ). Also given in Figure 5a was the flow rate profile during the 2-s period. Two features in Figure 5a are worth noting: first, the maximum temperature in the middle of the 2-s period showed considerable fluctuation, reflecting the fact that the burning events with the maximum temperature were short-lived and hence the profile was possibly a collection of many events; secondly, these burning events appeared to have quite high temperatures, e.g., most of them more than $1100{ }^{\circ} \mathrm{C}$ with some reaching $1200{ }^{\circ} \mathrm{C}$. Figure $5 \mathrm{~b}$ shows a scaled thermal image of the cigarette periphery corresponding to the time $0 \mathrm{~s}$ in Figure 5 a (frame 60 , about $0.08 \mathrm{~s}$ or 4 frames ahead of the start of the puff). The cigarette coal was in smouldering state and its temperature distribution was rather uniform. The dashed line marks the paper burn line. The coloured temperature scale in Figure 5b had a lower limit of $213{ }^{\circ} \mathrm{C}$, which was set by a pre-selected temperature range $\left(350\right.$ to $\left.1200{ }^{\circ} \mathrm{C}\right)$; the software automatically displayed $213{ }^{\circ} \mathrm{C}$ rather than $350{ }^{\circ} \mathrm{C}$, probably for easier viewing. The higher temperature limit could either be fixed or left to match the maximum temperature measured, also to aid visual interpretation of the temperature distribution.
The entire temperature profile of the puff may be further divided into three stages as shown in Figure 5a: a starting stage where initial air influx began to cause a fast rise in the maximum temperature; a middle stage where the maximum temperature fluctuated around about $1100{ }^{\circ} \mathrm{C}$ as the flow rate covered the upper part of the bell-shape profile; and a finishing stage where the maximum temperature dropped gradually following the decrease of the flow rate towards the end of the 2-s period. Some detailed features in each of the three stages are summarised below.

The beginning of the puff - localised cooling/heating: Figure 6 shows a series of four images from the start of the puff (at 4 frames or $0.08 \mathrm{~s}$ apart). At the onset of the puff ( $0.14 \mathrm{~s}$ into the puff, Figure $4 \mathrm{a})$ the temperature distribution was almost equally uniform as that shown in Figure 5b. As the puff progressed (Figures $4 \mathrm{~b}$ to $4 \mathrm{~d}$ ), temperatures at some regions (e.g., as indicated by the white circle) started to rise whereas temperatures at regions immediately adjacent to them actually fell. The maximum/average/minimum temperature profiles measured from the circled area shown in Figure 6e confirmed the observation. Apart from the maximum temperature, both the averaged and minimum temperatures showed a clear decrease lasting for about 0.3 to $0.4 \mathrm{~s}$. The decrease in the minimum temperature eventually stopped at ca. $400{ }^{\circ} \mathrm{C}$ after $0.5 \mathrm{~s}$ into the puff. The shape of the regions that became brighter (rising in temperature) in these images appeared to be tobacco shreds or strands, whereas those that became darker (decreasing in temperature) were gaps or voids between the tobacco shreds. Most cigarette paper around this area was already combusted and was unlikely to cause any of the observations discussed above. This suggested that the simultaneous localised cooling/heating phenomenon at the beginning of the puff was due to a combination of the ambient air being drawn into the voids between tobacco shreds (hence cooling) and the enhanced combustion of tobacco shreds experiencing higher oxygen supply. This was in fact a direct visualisation of the solid-phase (tobacco shreds) and the gas-phase (ambient air) temperatures as it was first described by BAKER using two different temperature probes $(3,4)$. There was, however, a fundamental difference between the gas-phase temperature measured here and those measured by a thermocouple. The gas-phase temperature measured here reflected the thermal emission by the solid materials forming (or surrounding) the voids as it was altered by the cooler air influx, whereas a thermocouple measured the gas temperature via convection. Hence it may be more appropriate to call the present observation a quasigas-phase temperature.

The middle of the puff - transient burning events: Figure 7 shows another image sequence from the middle of the puff. As reflected by the fluctuations in the maximum temperature (Figure 5a), this stage saw some transient high-temperature burning events against the background of higher air influx (or flow rate). To highlight the transient nature of these burning events, two random events are marked by arrows A and B in Figures 7a. Within $0.06 \mathrm{~s}$ (from Figure $7 \mathrm{a}$ to $7 \mathrm{c}$ ) event $\mathrm{A}$ declined from the brightest spot in the image to become average; a change of ca. 1250 degrees per second (roughly 10 times the average). At the same time, 


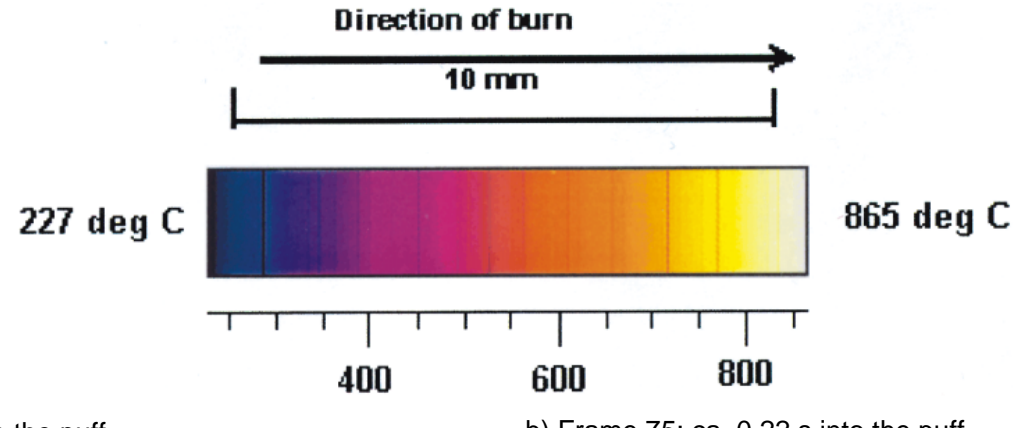

a) Frame $71:$ ca. $0.14 \mathrm{~s}$ into the puff

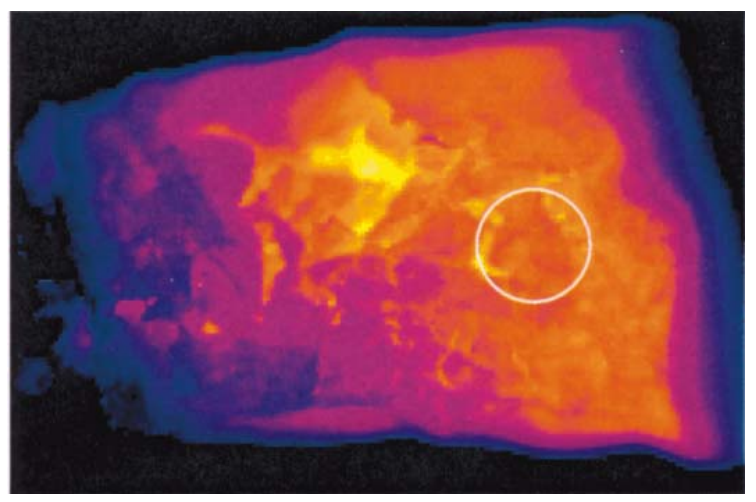

c) Frame 79: ca. $0.30 \mathrm{~s}$ into the puff

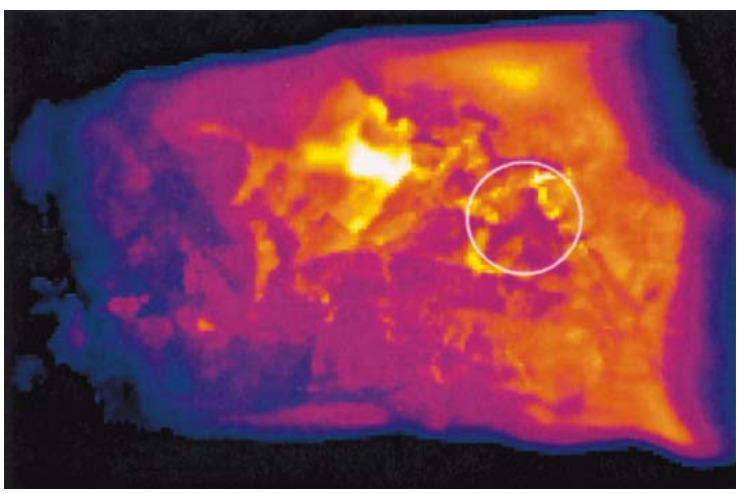

b) Frame 75: ca. $0.22 \mathrm{~s}$ into the puff

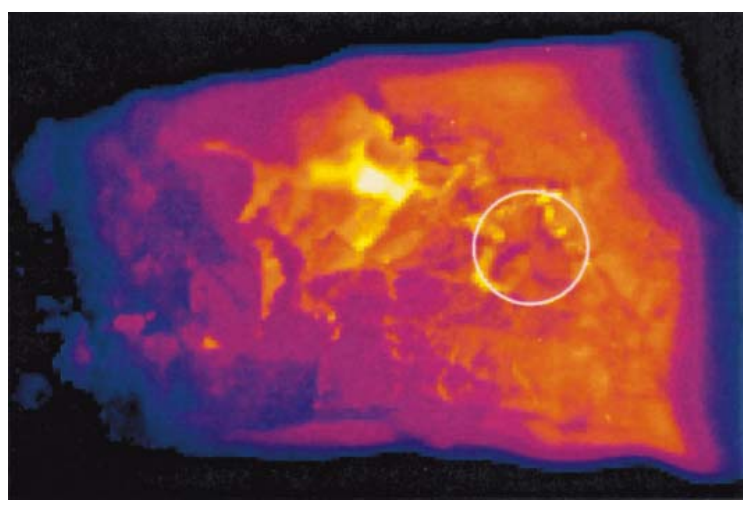

d) Frame 83: ca. $0.36 \mathrm{~s}$ into the puff

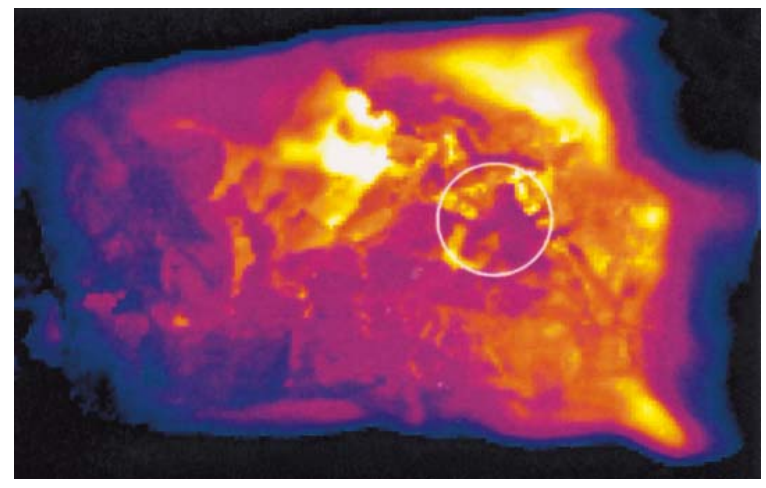

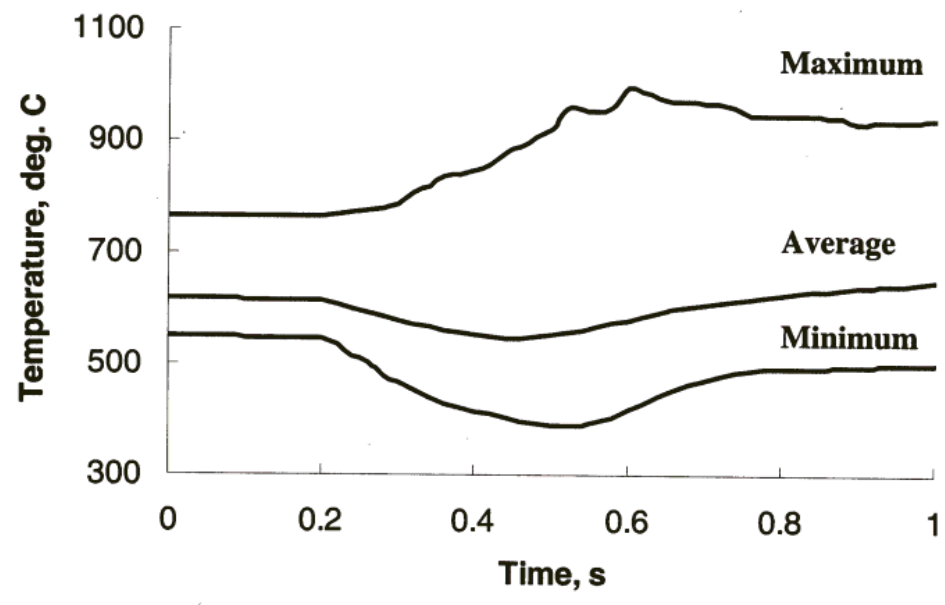

Figure 6. The start of the puff (cf. Figure 5a): an image sequence at 4 frames or 0.08 s intervals, illustrating simultaneous localised cooling and heating phenomenon 


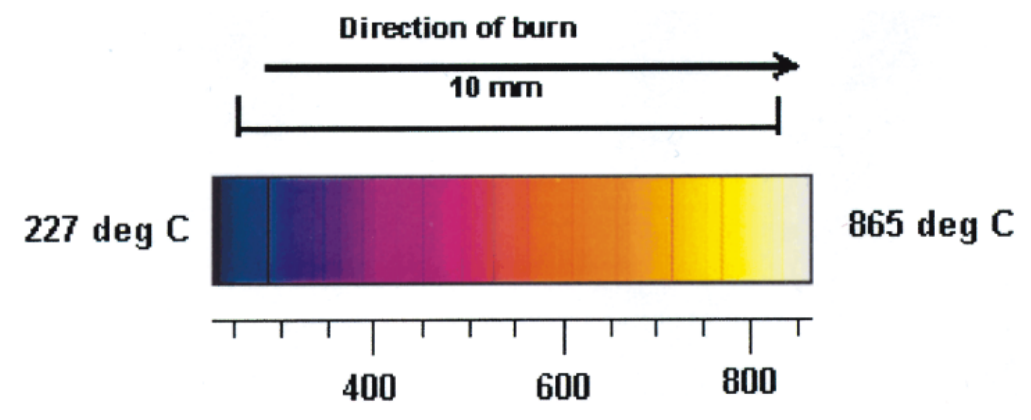

a) Frame 92: ca. $0.56 \mathrm{~s}$ into puff

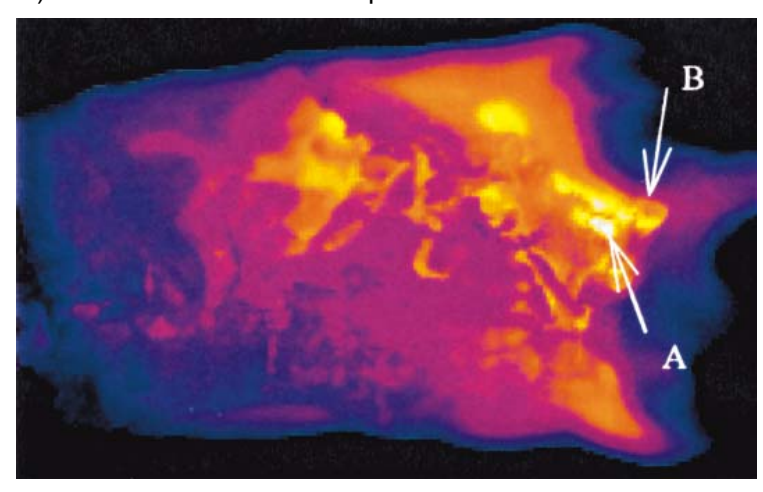

c) Frame 94: ca. $0.60 \mathrm{~s}$ into the puff

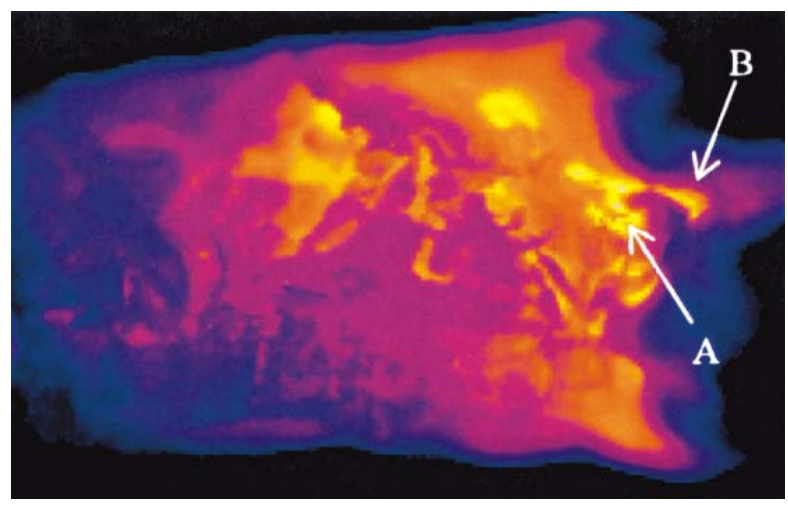

b) Frame 93: ca. $0.58 \mathrm{~s}$ into the puff

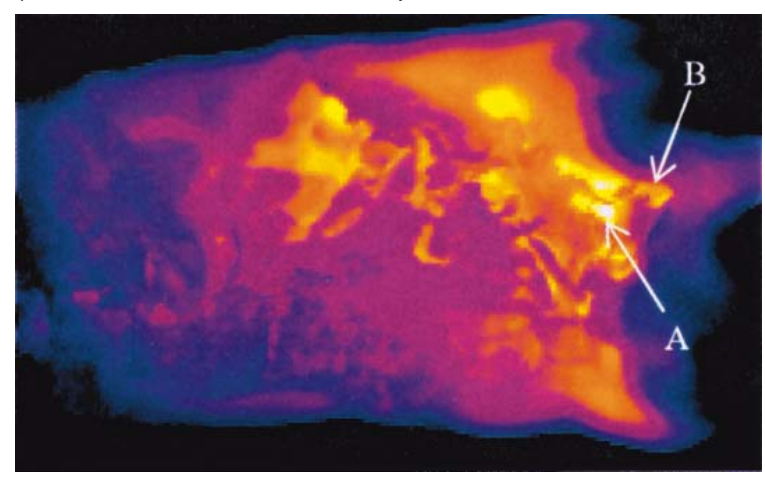

d) Frame 110: ca. $0.92 \mathrm{~s}$ into the puff

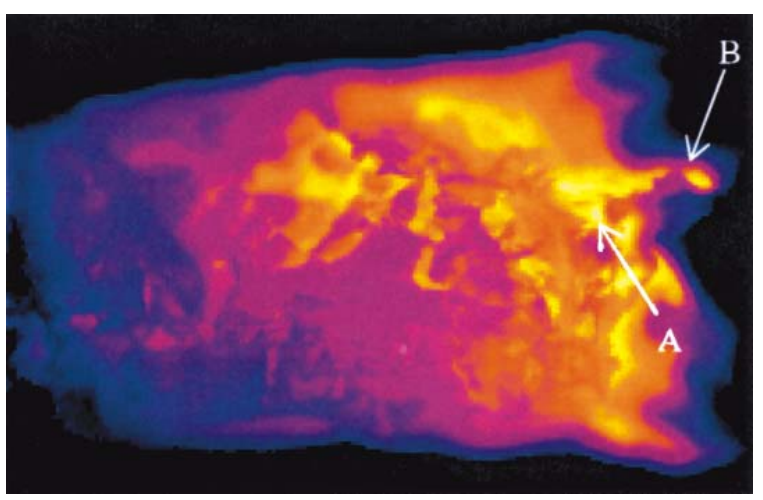

Figure 7. The middle of the puff (cf. Figure 5a): illustrating some fast, transient, high-temperature burning events marked by arrow $A$ and $B$

event B showed fast propagation towards the right. This kind of burning event would have been missed if either the image resolution, the response time, or the recording rate were lower. It would also be very difficult if not impossible for a thermocouple to detect events like these. This may explain the fact that previously reported maximum burning temperature of cigarettes rarely exceeded $1000{ }^{\circ} \mathrm{C}$ unless a special technique such as X-rays was used (5). These transient, high-temperature burning events were therefore more common than previously thought. They were linked to the combustion of tobacco shreds situated close to the periphery of the cigarette, hence experiencing the highest air influx during puffing. Figure $7 d$ (0.92 s into the puff) showed that larger regions in the central image appeared to be brighter and more uniform, as the heat released by combustion was able to raise the overall temperature of the coal by that time. Almost all tobacco shreds near the cigarette surface existing before the puff were consumed and new transient, high-temperature burning events had to come from fresh tobacco shreds entering the combustion. And the decreasing flow rate made them less likely to occur.

The end of the puff-temperature equilibrium: Two frames from the end of the puff are shown in Figure 8. The overall temperature distribution became more uniform at this stage, as both the tobacco shreds and the voids became less obvious. The maximum temperature slowly decayed and the paper burn line became gradually straighter in Figure 8 b. On average the paper burn line moved ca. $2.8 \mathrm{~mm}$ towards the right. The maximum temperature at the end of the 2-s puff reached about $940{ }^{\circ} \mathrm{C}$, already close to the average puff temperature commonly quoted in the literature. The temperature took considerably longer than 2-s to return to the prior-puff (smouldering) level. 


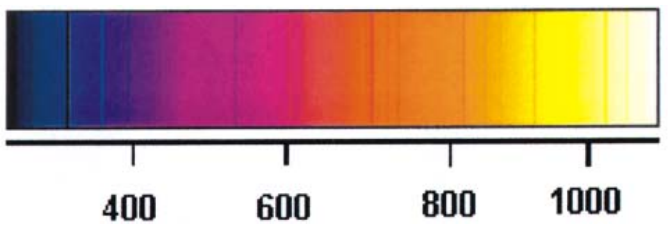

a) Frame 140: ca. $1.66 \mathrm{~s}$ into the puff

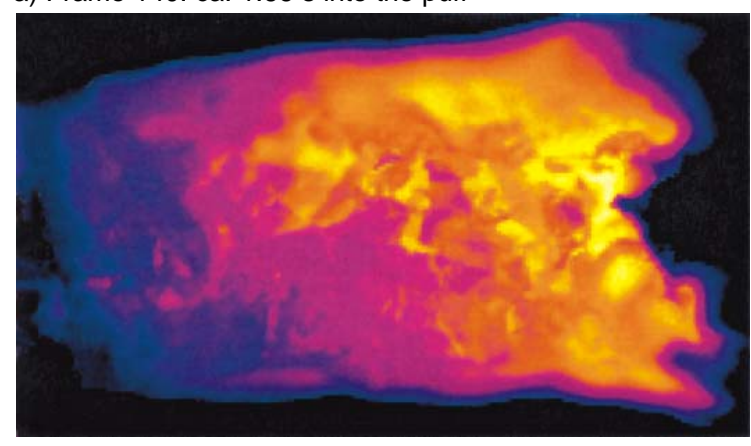

b) Frame $175:$ ca. $2.36 \mathrm{~s}$ into the puff

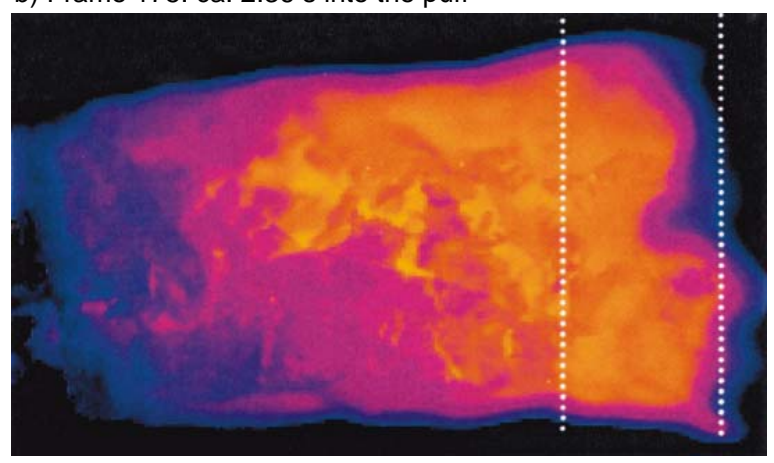

$t=0 \mathrm{~s} \quad \mathrm{t}=\mathbf{2 . 3 6 \mathrm { s }}$

Figure 8. The end of the puff (cf. Figure 5a): showing the transition to uniform paper burn line and overall temperature equilibrium.

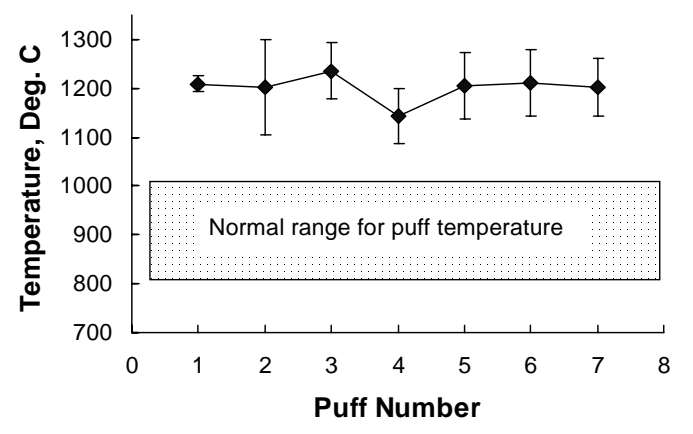

Figure 9. A graph illustrating the large difference between the maximum puff temperature recorded by the AGEMA system and those commonly reported in the literature (the shaded area). The data shown were averaged from 10 repeating measurements and the error bars represent the standard deviation.

Presenting cigarette's burning temperature by series of detailed temperature maps in both time and space was a method extensively used by BAKER $(1,3,4)$, as it reflected the real nature of cigarette combustion. Many observations made in this work were qualitatively similar to those made earlier (1-7). But the results in this work so far demonstrate that modern infrared systems are simpler and more powerful than, e.g., the thermocouple technique, and can reveal some intricate details in the peripheral burning of a cigarette. Using the technique we were also able to confirm the presence of the transient, high-temperature burning events situated near the surface (or a shallow region close to the surface), first discovered by EGERTON et al. (5). Their existence in the inner coal was very unlikely and their effects on the smoke chemistry are presently unknown.

\section{Average burning temperatures}

In the earlier literature the maximum temperature measured by a thermocouple or an infrared technique was often quoted as "the combustion temperature" of a cigarette for a puff or during smouldering and used to compare the combustion characteristics of different cigarettes (8). The relatively inferior resolutions of older techniques effectively provided the average over an area (infrared) or a volume (thermocouple) or time (for both techniques at slower recording rates). Thus a direct comparison between the "maximum combustion temperature" obtained by the older techniques with that obtained by this work revealed a large difference, as shown in Figure 9. Understandably, the present maximum temperature was dominated by those transient, high-temperature burning events and the situation can only reach a compromise if "an average" burning temperature can be obtained in this work over a large enough (hence representative), accurately focused area.

The image resolution of the AGEMA system was fixed at 8 bits for all recording rates; hence resolution-averaging or time-averaging (i.e., reducing recording rate) was not applicable. The only option was to take an average over a focused area. Knowing the diameter of the cigarette and the focus depth of the camera $(1.4 \mathrm{~mm})$ allowed an estimation of the maximum focused area (ca. $6 \mathrm{~mm}$ high strip along the cigarette rod), bearing in mind that the coal is coneshaped. Figure 10a shows a square area of $3 \mathrm{~mm}$ by $3 \mathrm{~mm}$ used to obtain the average burning temperature data plotted in Figure 10b. The square was moved as the puff progressed to maintain its position just behind the burn line. Other shapes or sizes may also be used as long as that the measurements are accurate and representative. The maximum puff temperatures after such averaging (Figure 10b) were about $200{ }^{\circ} \mathrm{C}$ lower than the original puffing tempera- 
a)

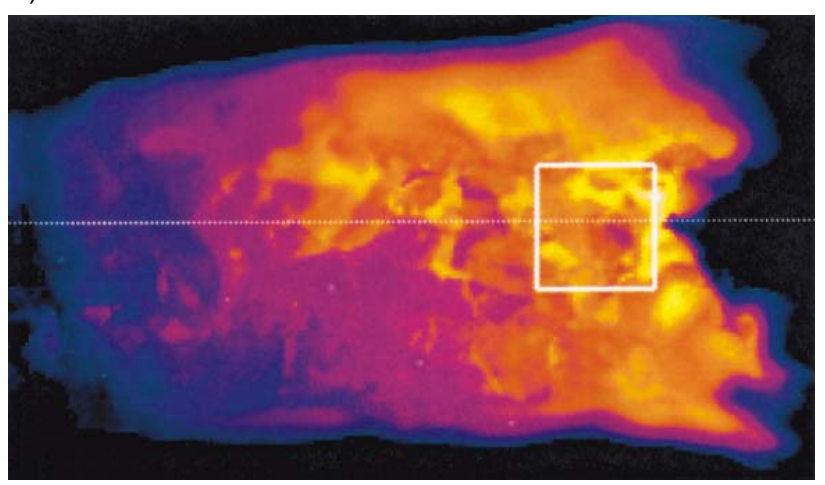

b)

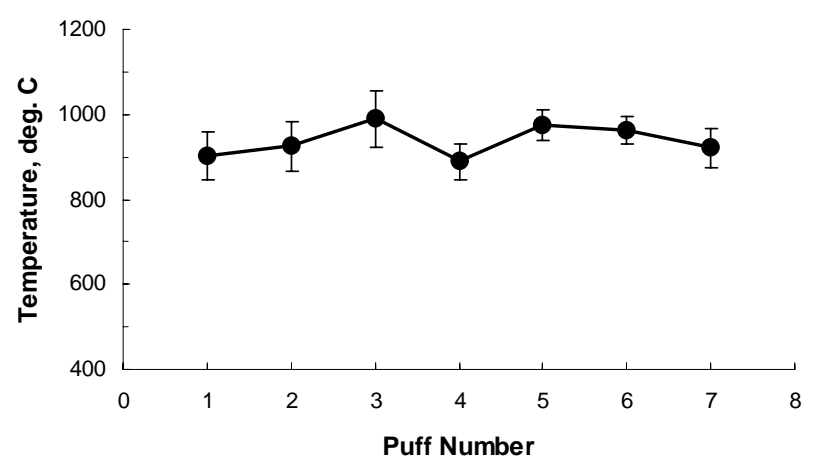

Figure 10. The white square in (a) was the area used to obtain the average burning temperature plotted in (b). The error bars represent $95 \%$ confidence level over ten measurements.

ture (Figure 9) and comparable to the commonly quoted burning temperatures in the literature $(3,4)$. A dip in temperature around the 4th puff is shown in both Figures 8 and 9; this was due to falling of cigarette ash.

The transient, high-temperature burning events were largely absent during smouldering, hence the maximum temperatures obtained by the AGEMA system should be comparable to those known smouldering temperatures; the results in Figure 11 confirmed this.

\section{CONCLUSION}

A modern infrared (AGEMA THV570 from AGEMA Infrared Systems, Sweden) system has been used in this work examining the peripheral burning of cigarettes. The main conclusions are

- The presence of some transient, high-temperature burning events has been confirmed. They were caused by the combustion of tobacco shreds near to the outer surface and experiencing the maximum air influx.

- To use a modern infrared system for measuring cigarette's burning temperature, one may use thermal images to accurately map its distribution. Alternatively, if a single average burning temperature is required, this can be obtained by averaging over an accurately focused area from the thermal images.

The improved resolution may be a useful tool for research into the causes of ignition propensity of different cigarettes where interaction between a smouldering cigarette and other materials takes place. A common limitation of all

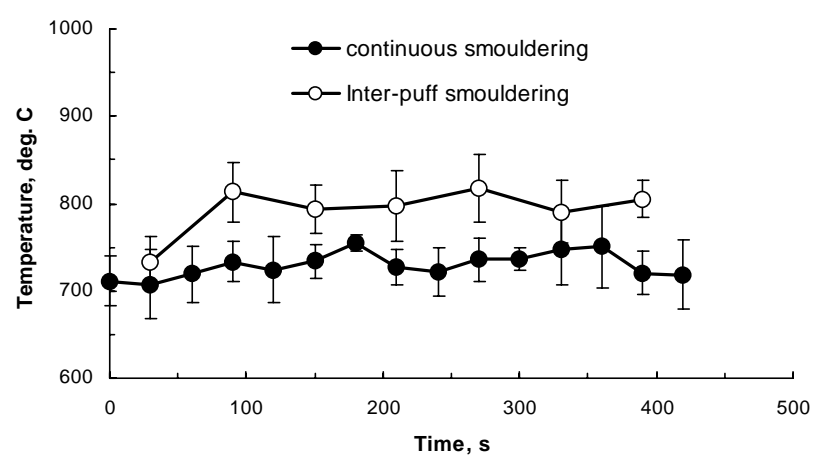

Figure 11. Smouldering temperatures measured by the AGEMA system under two different smouldering conditions

infrared technique is that it remains largely a surface technique although the AGEMA system also demonstrated its ability to detect sub-surface temperatures.

Acknowledgement: The authors would like to thank Dr R R. Baker (BAT, Southampton, UK) for commenting on the original manuscript.

\section{REFERENCES}

1. Baker, R.R.: Temperature distribution inside a burning cigarette; Nature 247 (1974) 405-406.

2. Lendvay, A.T. and T.S. Laszlo: Cigarette peak coal temperature measurements; Beitr. Tabakforsch. 7 (1974) 276-281.

3. Baker, R.R.: Temperature variation within a cigarette combustion coal during the smoking cycle; High. Temp. Sci. 7 (1975) 236-247.

4. Baker, R.R.: Combustion and thermal decomposition regions inside a burning cigarette; Combust. Flame 30 (1977) 21-32.

5. Egerton, A., K. Gugan and F.J. Weinberg: The mechanism of smouldering in cigarettes; Combust. Flame 7 (1963) 63-78.

6. Baker, R.R.: Mechanisms of smoke formation and delivery; Rec. Adv. Tob. Sci., 6 (1980) 184-224.

7. Baker, R.R. and D.P. Robinson: Tobacco combustion - the last ten years; Rec. Adv. Tob. Sci. 16 (1990) $3-71$.

8. Wynder, E.L. and D. Hoffmann: Tobacco and tobacco smoke; Academic Press, New York \& London, 1967, pp. $127-130$.

Address for correspondence:

Chuan Liu

British American Tobacco

$R \& D$ Centre

Regents Park Road

Millbrook, Southampton SO15 8TL

United Kingdom 